\title{
Seroprevalencia de agentes virales del Complejo Respiratorio Bovino en razas criollas del Centro de Investigación Turipaná de AGROSAVIA
}

Matiluz Doria-Ramos ${ }^{\mathrm{a} *}$

Teresa Oviedo-Socarras ${ }^{b}$

Misael Oviedo-Pastrana ${ }^{\mathrm{a}}$

Diego Ortiz-Ortega ${ }^{c}$

a Corporación Colombiana de Investigación Agropecuaria - AGROSAVIA, Centro de investigación Turipaná, Km 13 vía Montería. Cereté, Córdoba, Colombia.

${ }^{\mathrm{b}}$ Universidad de Córdoba. Facultad Medicina Veterinaria y Zootecnia. Departamento de Ciencias Pecuarias. Montería, Colombia.

${ }^{c}$ Corporación Colombiana de Investigación Agropecuaria - AGROSAVIA. Centro de Investigación Tibaitatá, Mosquera-Cundinamarca. Colombia.

* Autor de correspondencia: mdoriar@agrosavia.co

\section{Resumen:}

Se realizó un estudio descriptivo de corte transversal para determinar la prevalencia y factores epidemiológicos asociados con las enfermedades virales del Complejo Respiratorio Bovino (CRB) en razas criollas del Centro de Investigación Turipaná - AGROSAVIA (Colombia). Se evaluaron 403 bovinos de la raza Romosinuano y 445 Costeño con Cuernos (CCC). A través de la técnica de ELISA indirecta se determinó la presencia de anticuerpos para diarrea viral bovina (DVB), rinotraqueitis infecciosa bovina (IBR), parainfluenza-3 (PI3) y virus sincitial respiratorio bovino (BRSV). Se obtuvieron las prevalencias y se evaluó la asociación entre los agentes virales y entre estos con las variables sexo, edad, tipo de hato y raza; la prueba de Ji-cuadrada se aplicó con un nivel de significancia del 5\% y el efecto de la asociación fue determinado por la razón de probabilidades (OR). se constituyó un modelo de 
regresión logística para explicar la enfermedad más prevalente. Las prevalencias medias en las dos razas fueron: DVB (33.02 \%), BRSV (18.51\%), IBR (12.85\%) y PI3 (11.20 \%); sin embargo, individualmente, la raza CCC presentó mayor prevalencia para todas las enfermedades. El modelo de regresión mostró una asociación entre DVB, IBR y PI3, las variables sexo, edad, hembras con más de 1 año de edad y la raza CCC. Para abordar las enfermedades del CRB, se recomiendan acciones con énfasis en el control y prevención de DVB y estudios más profundos para entender la dinámica y co-endemicidad de la DVB, IBR, BRSV y PI3 en las razas estudiadas.

Palabras clave: Seroprevalencia, Complejo respiratorio bovino, Enfermedad respiratoria bovina, Romosinuano, Costeño con Cuernos.

Recibido: 20/11/2018

Aceptado: 23/09/2019

\section{Introducción}

La enfermedad del complejo respiratorio bovino (CRB) es una de las principales causas de pérdidas económicas en las explotaciones ganaderas ${ }^{(1)}$. Estas pérdidas se atribuyen a la disminución de la eficiencia productiva, los costos del tratamiento, el aumento del trabajo de parto y la muerte de los animales debido a la neumonía ${ }^{(2)}$. El desarrollo de CRB está asociado con factores ambientales (manejo, estrés y alimentación), factores específicos del individuo (edad, condición corporal e inmunidad) y la acción de agentes infecciosos (virus, bacterias y parásitos $)^{(1)}$. Los agentes virales asociados con CRB incluyen el virus de la IBR, PI3, BRSV y $\operatorname{DVB}^{(3)}$.

La enfermedad respiratoria se produce cuando un virus patógeno infecta al hospedero y permite que las bacterias oportunistas, normalmente presentes en el tracto respiratorio superior, invadan los pulmones y produzcan neumonía grave y la muerte. Estas bacterias incluyen Pasteurella multocida, Mannheimia haemolytica, Mycoplasma bovis e Histophilus somni ${ }^{(1)}$.

Estudios epidemiológicos en el municipio de Montería, departamento de Córdoba, determinaron la seroprevalencia de los virus asociados con CRB, siendo de $74.7 \%$ para $\mathrm{IBR}^{(4)}, 29.4 \%$ para $\mathrm{BVD}^{(5)}, 13.5 \%$ para PI-3 ${ }^{(6)}$ y $13 \%$ para $\mathrm{BRSV}^{(7)}$.

El objetivo de este estudio fue analizar la presencia de los virus de la DVB, IBR, PI3 y BRSV, implicados en el CRB y los factores epidemiológicos asociados en las dos razas bovinas 
Rev Mex Cienc Pecu 2020;11(3):771-782

criollas en el centro de investigación Turipaná de AGROSAVIA, en el municipio de Cereté, Córdoba.

\section{Material y métodos}

\section{Sitio de estudio}

El estudio se realizó en el centro de investigación Turipaná de AGROSAVIA, ubicado a 850'79 N y -7547'58" O, en el municipio de Cereté, departamento de Córdoba, Colombia. El área está clasificada como bosque tropical seco, tiene una altitud de $14 \mathrm{msnm}$, temperatura promedio de $27.5^{\circ} \mathrm{C}$, humedad relativa de $81 \%$ y precipitación promedio anual de $1,340 \mathrm{~mm}$, donde el $85 \%$ de la lluvia cae entre los meses de abril y noviembre ${ }^{(8)}$.

\section{Tipo de estudio y tamaño de muestra}

Se realizó un estudio epidemiológico descriptivo de tipo transversal entre todos los animales de las dos razas criollas, Romosinuano (403 animales) y Costeño Con Cuernos (445 animales), en el centro de investigación Turipaná de AGROSAVIA. El estudio se realizó en mayo a octubre de 2016.

\section{Procesamiento de muestras}

Después de la desinfección del área, se recogieron $5 \mathrm{ml}$ de sangre de la vena coccígea, en tubos vacutainer ${ }^{\circledR}$ sin anticoagulante. Las muestras se marcaron con el número del animal y la fecha de recolección y se almacenaron a una temperatura de $4{ }^{\circ} \mathrm{C}$. Posteriormente, se centrifugaron a 3,500 rpm durante 5 min para obtener suero, luego se colocaron en viales y se almacenaron a $-20{ }^{\circ} \mathrm{C}$ hasta un análisis posterior. Se procesaron en el laboratorio en el centro de investigación Tibaitatá de AGROSAVIA, en el departamento de Cundinamarca, utilizando kits comerciales de prueba ELISA (Synbiotics ${ }^{\circledR}$ para BVD e IBR, Biox Prionics ${ }^{\circledR}$ para BRSV y PI3) siguiendo las recomendaciones del fabricante.

\section{Análisis de datos}

El estudio de prevalencia se acompañó de una encuesta epidemiológica encaminada a determinar factores que podrían tener asociación con las patologías en estudio; se analizaron los factores sexo, raza (Romosinuano y CCC), edad ( $<1$ año y > 1 año) y tipo de hato (Banco de germoplasma y Mejoramiento genético). Estos factores se asociaron de forma univariada con los resultados serológicos (positivo o negativo) de cada uno de los agentes infecciosos estudiados; se aplicó el estadístico Ji-cuadrada y un nivel de significancia de 0.05; 
adicionalmente, se determinaron las medidas de razón de probabilidades. Finalmente, se construyó un modelo de regresión logística para explicar la correlación entre los factores y las enfermedades estudiadas; como variable respuesta se seleccionó la enfermedad que tuvo la mayor prevalencia. Los datos se analizaron utilizando el software EpiInfo 7.2.1.0 ®.

\section{Resultados y discusión}

Los virus de la DVB, IBR, PI3 y BRSV, que hacen parte del complejo CRB han sido reportados en diferentes granjas ganaderas en Colombia, sin embargo, este estudio es el primero que busca determinar su prevalencia en las razas criollas Romosinuano y CCC. Se afirma que estas razas son resistentes y bien adaptadas a las condiciones ecológicas del trópico bajo en la costa norte de Colombia ${ }^{(9,10)}$, no obstante, ambas presentaron seroprevalencia para las cuatro enfermedades virales del complejo $\mathrm{CRB}$, siendo la $\mathrm{CCC}$ la más susceptible (Cuadro 1).

EL virus con mayor presencia en ambas razas fue el de la DVB con una prevalencia de $33.60 \%$, continuando casi con la mitad de porcentaje el virus BRSV (18.51\%), mientras los agentes con menor presencia fueron IBR y PI3 con prevalencias de $12.8 \%$ y $11.20 \%$, respectivamente.

Cuadro 1: Seroprevalencia de las enfermedades virales del CRB en las razas criollas del C.I Turipaná $(\%)$

\begin{tabular}{llllll}
\hline Enfermedad & Variables & Categorías & n+ & n- & Seroprevalencia \\
\hline \multirow{2}{*}{ DVB } & \multirow{2}{*}{ Raza } & Romosinuano & 100 & 303 & 24.81 \\
& & CCC & 185 & 265 & 40.45 \\
\hline \multirow{2}{*}{ BRSV } & \multirow{2}{*}{ Raza } & Romosinuano & 60 & 343 & 14.89 \\
& \multirow{2}{*}{ IBR } & CCC & 97 & 348 & 21.80 \\
& \multirow{2}{*}{ Raza } & Romosinuano & 47 & 356 & 11.66 \\
& \multirow{2}{*}{ Raza } & CCC & 62 & 383 & 13.93 \\
& & Romosinuano & 29 & 374 & 7.20 \\
& & CCC & 66 & 379 & 14.83 \\
\hline
\end{tabular}

Al igual que en este estudio, se ha confirmado una alta seroprevalencia para DVB en otras regiones de Colombia; un estudio previo en el municipio de Montería reportó un $29.5 \%$ de seropositividad $^{(6)}$ y otro en el departamento de Cesar obtuvo resultados de $46 \%{ }^{(11)}$. 
Se cree que el BRSV prevalece en las poblaciones bovinas de todo el mundo. Estudios sobre este virus en animales con antecedentes de infertilidad en Montería obtuvieron seroprevalencias del $13 \%{ }^{(5)}$ y en terneros recién nacidos $31 \%^{(12)}$. En Inglaterra, el $83 \%$ del ganado tiene anticuerpos y en los Estados Unidos está implicado en más del $50 \%$ de las enfermedades respiratorias del ganado de engorde ${ }^{(13)}$.

La prevalencia de IBR en bovinos ha sido reportada históricamente en varias regiones de Colombia. En 1982 se encontró seropositividad de $51.7 \%$ en la región Caribe, $21.5 \%$ en la región Andina y el $20.6 \%$ en el Pie de Monte Llanero ${ }^{(14)}$. Recientemente, se reportaron prevalencias de $55.5 \%$ en la región de Magdalena ${ }^{(15)}$ y $35.65 \%$ en el municipio de Toca Boyacá $^{(16)}$. De los reportes analizados, las seroprevalencias más altas para este virus han sido reportadas en el municipio de Montería, donde se encontró $74.7 \%$ de seroprevalencia en hembras con antecedentes de infertilidad ${ }^{(4)}$ y $60 \%$ en terneros recién nacidos ${ }^{(12)}$.

El virus de la PI-3 es uno de los patógenos respiratorios virales más importantes del ganado joven y adulto asociado con el $\mathrm{CRB}^{(17)}$. En el municipio de Montería se ha informado una prevalencia del $13.5 \%$ en bovinos de doble propósito ${ }^{(7)}$ y $41 \%$ en terneros recién nacidos ${ }^{(12)}$; en el departamento de Antioquia en la raza criolla Blanco Orejinegro, se reportó una prevalencia de $68.9 \%{ }^{(18)}$. Seroprevalencias del $44.6 \%$ fueron encontradas en Argentina ${ }^{(2)}$ y $81.8 \%$ en Perú ${ }^{(19)}$.

El análisis univariado de los factores estudiados sobre las diferentes enfermedades del CRB se presenta en los Cuadros 2,3,4 y 5. La mayor susceptibilidad de las hembras a las enfermedades del CRB podría explicarse como consecuencia al alto número de manejos realizados en hembras, debido a una mayor demanda productiva y reproductiva. Los factores asociados con el ordeño, la inseminación artificial y la transferencia de embriones se consideran factores de estrés que pueden hacer que las hembras sean más susceptibles a las enfermedades en comparación con los machos ${ }^{(20)}$. 
Rev Mex Cienc Pecu 2020;11(3):771-782

Cuadro 2: Análisis univariado de factores asociados al virus de la DVB en el hato bovino criollo del Centro de Investigación Turipaná de Corpoica

\begin{tabular}{|c|c|c|c|c|c|c|c|}
\hline \multirow{2}{*}{ Variables } & \multirow{2}{*}{ Categorías } & \multirow{2}{*}{$\mathbf{n +}$} & \multirow{2}{*}{ n- } & \multirow{2}{*}{$P$-valor } & \multirow{2}{*}{ OR } & \multicolumn{2}{|l|}{ IC $95 \%$} \\
\hline & & & & & & Inferior & Superior \\
\hline \multirow{2}{*}{ Sexo } & Macho & 41 & 232 & \multirow{2}{*}{$<0.001$} & \multirow{2}{*}{4.025} & \multirow{2}{*}{2.776} & \multirow{2}{*}{5.833} \\
\hline & Hembra & 239 & 336 & & & & \\
\hline \multirow{2}{*}{ Edad } & $<1$ año & 47 & 185 & \multirow{2}{*}{$<0.001$} & \multirow{2}{*}{2.395} & \multirow{2}{*}{1.672} & \multirow{2}{*}{3.430} \\
\hline & $>1$ año & 233 & 383 & & & & \\
\hline \multirow{2}{*}{ Hato } & $\begin{array}{l}\text { Mejoramiento } \\
\text { Genético }\end{array}$ & 11 & 71 & \multirow{2}{*}{$<0.001$} & \multirow{2}{*}{3.493} & \multirow{2}{*}{1.819} & \multirow{2}{*}{6.706} \\
\hline & $\begin{array}{l}\text { Banco } \\
\text { Germoplasma }\end{array}$ & 269 & 497 & & & & \\
\hline \multirow{2}{*}{ Raza } & Romosinuano & 100 & 303 & \multirow{2}{*}{$<0.001$} & \multirow{2}{*}{2.058} & \multirow{2}{*}{1.532} & \multirow{2}{*}{2.763} \\
\hline & $\mathrm{CCC}$ & 180 & 265 & & & & \\
\hline
\end{tabular}

Cuadro 3: Análisis univariado de factores asociados al virus de la IBR en el hato bovino criollo del Centro de Investigación Turipaná de AGROSAVIA

\begin{tabular}{|c|c|c|c|c|c|c|c|}
\hline \multirow{2}{*}{ Variables } & \multirow{2}{*}{ Categorías } & \multirow{2}{*}{$\mathbf{n}+$} & \multirow{2}{*}{ n- } & \multirow{2}{*}{$\begin{array}{l}P \text { - } \\
\text { valor }\end{array}$} & \multirow{2}{*}{ O.R } & \multicolumn{2}{|l|}{ IC $95 \%$} \\
\hline & & & & & & Inferior & Superior \\
\hline \multirow{3}{*}{ Sexo } & Macho & 26 & 247 & & & & \\
\hline & Hembra & 83 & 492 & 0.045 & 1.602 & 1.005 & 2.554 \\
\hline & $<1$ año & 37 & 195 & & & & \\
\hline \multirow[t]{2}{*}{ Edad } & $>1$ año & 72 & 544 & 0.098 & 0.698 & 0.454 & 1.071 \\
\hline & $\begin{array}{l}\text { Mejoramiento } \\
\text { Genético }\end{array}$ & 11 & 71 & & & & \\
\hline \multirow[t]{2}{*}{ Hato } & $\begin{array}{l}\text { Banco } \\
\text { Germoplasma }\end{array}$ & 98 & 668 & 0.873 & 0.946 & 0.484 & 1.849 \\
\hline & Romosinuano & 47 & 356 & & & & \\
\hline Raza & $\mathrm{CCC}$ & 62 & 383 & 0.324 & 1.226 & 0.817 & 1.839 \\
\hline
\end{tabular}


Rev Mex Cienc Pecu 2020;11(3):771-782

Cuadro 4: Análisis univariado de factores asociados al BRSV en el hato bovino criollo del Centro de Investigación Turipaná de Corpoica

\begin{tabular}{|c|c|c|c|c|c|c|c|}
\hline \multirow{2}{*}{ Variables } & \multirow{2}{*}{ Categorías } & \multirow{2}{*}{ n+ } & \multirow{2}{*}{ n- } & \multirow{2}{*}{$\begin{array}{l}P \text { - } \\
\text { valor }\end{array}$} & \multirow{2}{*}{ O.R } & \multicolumn{2}{|l|}{ IC $95 \%$} \\
\hline & & & & & & Inferior & Superior \\
\hline \multirow[b]{2}{*}{ Sexo } & Macho & 36 & 237 & \multirow{2}{*}{0.005} & \multirow{2}{*}{1.754} & \multirow{2}{*}{1.171} & \multirow{2}{*}{2.627} \\
\hline & Hembra & 121 & 454 & & & & \\
\hline \multirow[b]{2}{*}{ Edad } & $<1$ año & 50 & 182 & \multirow{2}{*}{0.162} & \multirow{2}{*}{0.765} & \multirow{2}{*}{0.525} & \multirow{2}{*}{1.115} \\
\hline & $>1$ año & 107 & 509 & & & & \\
\hline \multirow[b]{2}{*}{ Hato } & $\begin{array}{l}\text { Mejoramiento } \\
\text { Genético }\end{array}$ & 19 & 63 & \multirow{2}{*}{0.253} & \multirow{2}{*}{0.728} & \multirow{2}{*}{0.422} & \multirow{2}{*}{1.256} \\
\hline & $\begin{array}{l}\text { Banco } \\
\text { Germoplasma }\end{array}$ & 138 & 628 & & & & \\
\hline \multirow[b]{2}{*}{ Raza } & Romosinuano & 60 & 343 & \multirow{2}{*}{0.009} & \multirow{2}{*}{1.593} & \multirow{2}{*}{1.117} & \multirow{2}{*}{2.272} \\
\hline & $\mathrm{CCC}$ & 97 & 348 & & & & \\
\hline
\end{tabular}

Cuadro 5: Análisis univariado de factores asociados al virus PI3 en el hato bovino criollo del Centro de Investigación Turipaná de Corpoica

\begin{tabular}{|c|c|c|c|c|c|c|c|}
\hline \multirow[t]{2}{*}{ Variables } & \multirow[t]{2}{*}{ Categorías } & \multirow[t]{2}{*}{$\mathbf{n}+$} & \multirow[t]{2}{*}{ n- } & \multirow[t]{2}{*}{$P$-valor } & \multirow[t]{2}{*}{ O.R } & \multicolumn{2}{|l|}{ IC $95 \%$} \\
\hline & & & & & & Inferior & Superior \\
\hline \multirow[b]{2}{*}{ Sexo } & Macho & 9 & 264 & \multirow[b]{2}{*}{$<0.001$} & \multirow[b]{2}{*}{5.158} & \multirow[b]{2}{*}{2.554} & \multirow[b]{2}{*}{10.417} \\
\hline & Hembra & 86 & 489 & & & & \\
\hline \multirow[b]{2}{*}{ Edad } & $<1$ año & 10 & 222 & \multirow[b]{2}{*}{0.000} & \multirow[b]{2}{*}{3.554} & \multirow[b]{2}{*}{1.812} & \multirow[b]{2}{*}{6.971} \\
\hline & $>1$ año & 85 & 531 & & & & \\
\hline \multirow{4}{*}{ Hato } & Mejoramiento & & & \multirow{4}{*}{0.002} & \multirow{4}{*}{11.330} & \multirow{4}{*}{1.558} & \multirow{4}{*}{8.237} \\
\hline & Genético & 1 & 81 & & & & \\
\hline & Banco & & & & & & \\
\hline & Germoplasma & 94 & 672 & & & & \\
\hline \multirow[b]{2}{*}{ Raza } & Romosinuano & 29 & 374 & \multirow[b]{2}{*}{$<0.001$} & \multirow[b]{2}{*}{2.245} & \multirow[b]{2}{*}{1.418} & \multirow[b]{2}{*}{3.555} \\
\hline & $\mathrm{CCC}$ & 66 & 379 & & & & \\
\hline
\end{tabular}

La edad se asoció positivamente con BVD y PI3, siendo más afectados los animales $>1$ año (2.39 y 3.55 veces, respectivamente). Aunque el ganado es susceptible a la infección por BVD en todas las edades, es más probable que los animales mayores de un año sean seropositivos. Esto probablemente se deba a la disminución de la inmunidad pasiva derivada de los anticuerpos maternos y adicionalmente, a mayor tiempo de exposición a los patógenos involucrados en la enfermedad ${ }^{(21)}$. 
El tipo de hato también se asoció con BVD y PI3, en este sentido, el hato del Banco de Germoplasma se vio más afectado que el programa de Mejoramiento Genético (3.49 y 11.33 veces para BVD y PI3, respectivamente). La mayor susceptibilidad del ganado en el hato del Banco de Germoplasma podría explicarse por la mayor densidad de población en este grupo lo que favorece la dispersión aerógena de estos virus y a la mayor humedad en los potreros utilizados por estos animales también es un factor que favorece la presentación de la enfermedad $^{(22) \text {. }}$

El análisis univariado arrojó asociación estadística entre la variable raza y BVD, BRSV y PI3, siendo los CCC los de mayor seropositividad a estos tres agentes infecciosos en comparación con la raza Romosinuano. La raza CCC fue 2.05 veces más seropositiva a BVD, 1.59 veces más seropositiva a BRSV y 2.24 veces más seropositiva a PI3. Sin embargo, el análisis multivariado solo reveló una asociación estadísticamente significativa entre el CCC y la BVD $(\mathrm{OR}=1.845$, IC 95\% = 1.349-2.523, $P<0.001)$. No hay estudios que demuestren una mayor exposición sobre el CCC que Romosinuano a estos agentes infecciosos. Por lo tanto, se sugiere que se lleven a cabo estudios inmunológicos específicos para investigar más a fondo la susceptibilidad específica de la raza a estas enfermedades.

BVD y PI3 fueron los únicos agentes infecciosos que presentaron una asociación estadística con todas las variables estudiadas. Sin embargo, como BVD era más frecuente en los hatos estudiados, el modelo de regresión logística para las enfermedades virales del complejo BRD se basó en BVD.

El modelo de regresión logística (Cuadro 6) mostró que BVD tiene una asociación con el sexo hembra, animales mayores de un año y la raza CCC, lo que sugiere que estos factores podrían contribuir significativamente al desarrollo de estas infecciones. La asociación entre BVD, IBR y PI3 también se demostró. Los animales positivos a IBR tienen 3.04 veces más probabilidad de tener BVD, mientras que los animales PI3 positivos tienen 3.81 veces más posibilidades; sin embargo, debido al tipo de diagnóstico serológico y debido a que es un estudio transversal, no es posible detectar la relación causal entre las tres enfermedades, ni evaluar una secuencia temporal en su presentación. Aunque el modelo final mostró relevancia epidemiológica, los estadístico log-likelihood y Hosmer-Lemeshow indicaron un pobre ajuste del modelo; sin embargo, no se consideró la eliminación de variable debido a que todas las que quedaron en el modelo final tienen importancia epidemiológica, lo cual fue confirmado mediante la estadística univariada. Nuevos estudios epidemiológicos son necesarios para investigar más a fondo estos aspectos. 
Rev Mex Cienc Pecu 2020;11(3):771-782

Cuadro 6: Modelo de regresión logística para las enfermedades del CRB, con base en el virus de la DVB

\begin{tabular}{|c|c|c|c|c|c|}
\hline \multirow{2}{*}{ Variables } & \multirow{2}{*}{ Categorías } & \multirow{2}{*}{$P$-valor } & \multirow{2}{*}{ OR } & \multicolumn{2}{|l|}{ IC $95 \%$} \\
\hline & & & & Inferior & Superior \\
\hline \multirow{2}{*}{ Sexo } & Macho & \multirow{2}{*}{$<0.001$} & \multirow{2}{*}{3.833} & \multirow{2}{*}{2.587} & \multirow{2}{*}{5.678} \\
\hline & Hembra & & & & \\
\hline \multirow{2}{*}{ Edad } & $<1$ año & \multirow{2}{*}{$<0.002$} & \multirow{2}{*}{1.871} & \multirow{2}{*}{1.262} & \multirow{2}{*}{2.773} \\
\hline & $>1$ año & & & & \\
\hline \multirow{2}{*}{ Raza } & Romosinuano & \multirow{2}{*}{$<0.001$} & \multirow{2}{*}{2.564} & \multirow{2}{*}{1.846} & \multirow{2}{*}{3.561} \\
\hline & $\mathrm{CCC}$ & & & & \\
\hline IBR & $\begin{array}{l}\text { Negativo } \\
\text { Positivo }\end{array}$ & $<0.001$ & 3.045 & 1.659 & 5.589 \\
\hline PI3 & $\begin{array}{l}\text { Negativo } \\
\text { Positivo }\end{array}$ & $<0.001$ & 3.811 & 1.966 & 7.386 \\
\hline
\end{tabular}

\section{Conclusiones e implicaciones}

En conclusión, todos los principales agentes virales que participan en el complejo BRD están presentes en el ganado criollo del Centro de Investigación Turipaná. Se recomienda un plan de acción para controlar y prevenir estas enfermedades en el centro de investigación, con énfasis en el control y prevención de BVD; adicionalmente, se requieren más estudios de seguimiento para comprender la dinámica y los procesos de co-endemicidad de BVD, IBR, BRSV y PI3 en las razas Romosinuano y CCC.

\section{Agradecimientos}

Los autores agradecen al Sistema de Bancos de Germoplasma de la Nación para la Alimentación y la Agricultura (SBGNAA) con sede en el C.I. Turipaná de AGROSAVIA, por permitir el acceso a los bovinos usados en esta investigación.

\section{Conflicto de interés}

Los autores declaran la ausencia de cualquier conflicto de interés. 


\section{Literatura citada:}

1. Gershwin LJ, Van Eenennaam AL, Anderson ML, McEligot HA, Shao MX, ToaffRosenstein R et al. Single Pathogen Challenge with Agents of the Bovine Respiratory Disease Complex. PLoS One 2015; 10(11):142-479. https://doi.org/10.1371/journal.pone.0142479.

2. Carbonero A, Maldonado A, Perea A, García-Bocanegra I, Borge C, Torralbo A et al. Factores de riesgo del síndrome respiratorio bovino en terneros lactantes de Argentina. Arch Zoot 2011; 60 (229):41-51. https://dx.doi.org/10.4321/S000405922011000100005 .

3. Grissett GP, White BJ, Larson RL. Structured literature review of responses of cattle to viral and bacterial pathogens causing bovine respiratory disease complex. J Vet Intern Med 2015;29(3):770-780. http://doi.org/10.1111/jvim.12597.

4. Betancur C, González M, Reza L. Seroepidemiología de la rinotraqueitis infecciosa bovina en el municipio de Montería, Colombia. Rev MVZ Córdoba 2006;11(2):830836. https://doi.org/10.21897/rmvz.447.

5. Betancur H, Rodas J, González M. Estudio seroepidemiológico del virus respiratorio sincitial bovino en el municipio de Montería, Colombia. Rev MVZ Córdoba 2011;16(3):2778-2784. https://doi.org/10.21897/rmvz.278.

6. Betancur H, Gogorza LM, Martínez FG. Seroepidemiología de la diarrea viral bovina en Montería (Córdoba, Colombia). Analecta Vet 2007;27(2):11-16. http://sedici.unlp.edu.ar/handle/10915/11204.

7. Betancur H, Orrego A, González M. Estudio seroepidemiológico del virus de parainfluenza 3 en bovinos del municipio de Montería (Colombia) con trastornos reproductivos. Rev Mev Vet 2010;20: 63-70. https://doi.org/10.19052/mv.583.

8. Saraz GA. Influencia de los factores genéticos y ambientales en caracteres productivos y reproductivos de la raza criolla colombiana Romosinuano (No. Doc. 22372, CO-BAC, Bogotá). 2004.

9. Ossa G, Abuabara Y, García JP, Martínez G. El ganado criollo colombiano Costeño con Cuernos (CCC). Anim Genet Resour 2011;48:101-107.

10. Elzo MA, Manrique $\mathrm{C}$, Ossa G, Acosta $\mathrm{O}$. Additive and nonadditive genetic variability for growth traits in the Turipana Romosinuano $\times$ Zebu multibreed herd. J Anim Sci 1998;76:1539-1549. https://doi.org/10.2527/1998.7661539x. 
11. Peña IF. Estudio serológico de diarrea viral bovina en la microrregión del valle del Cesar. AICA 2011; 1:309-312. Disponible en: https://aicarevista.jimdo.com/.

12. Betancur HC, Castañeda TJ, González TM. Inmunopatología del complejo respiratorio bovino en terneros neonatos en Montería-Colombia. Rev Cient 2017;27(2):95-102.

13. Tjørnehøj K, Uttenthal Å, Viuff B, Larsen LE, Røntved C, Rønsholt L. An experimental infection model for reproduction of calf pneumonia with bovine respiratory syncytial virus (BRSV) based on one combined exposure of calves. Res Vet Sci 2003;74(1):5565. https://doi.org/10.1016/S0034-5288(02)00154-6.

14. Griffiths IB, Gallego M, Villamil L. Factores de infertilidad y pérdidas económicas en ganado de leche en Colombia (No. Doc. 4186)* CO-BAC, Santafé de Bogotá). 1982.

15. Piedrahita LE, Montoya LM, Pedraza FJ. Herpes Virus Bovino tipo 1 (BoHV-1) como posible causa de encefalitis en bovinos de la región del Magdalena Medio Colombiano: Estudio serológico y análisis epidemiológico. Rev Colom Cienc Pecu 2010;23(2):191198.

16. Ochoa X, Orbegozo M, Manrique F, Pulido M, Ospina J. Seroprevalencia de rinotraqueitis infecciosa bovina en hatos lecheros de Toca - Boyacá. Rev MVZ Córdoba 2012;17(2):2974-2982.

17. Sobhy NM, Mor SK, Bastawecy IM, Fakhry HM, Youssef CRB, Goyal SM. Surveillance, isolation and complete genome sequence of bovine parainfluenza virus type 3 in Egyptian cattle. Int $J$ Vet Sci Med 2017;5(1):8-13. doi: 10.1016/j.ijvsm.2017.02.004.

18. Molina SH, Castaño J, Arboleda J, Cadavid J, Zapata M. Estudio serológico para el virus de parainfluenza-3 en el hato BON en el departamento de Antioquia. Rev Colomb Cienc Pecu 1998;11(2):81-86.

19. Cabello R, Quispe Ch, Rivera G. Frecuencia de los virus Parainfluenza-3, Respiratorio Sincitial y Diarrea Viral Bovina en un rebaño mixto de una comunidad campesina de Cusco. RIVEP 2006;17(2):167-172. http://dx.doi.org/10.15381/rivep.v17i2.1535.

20. Chamizo EG. Leucosis bovina enzootica: Revisión. REDVET 2005;6(7):21-25. http//www.redalyc.org/articulo.oa?id=63612652016.

21. Ellis J, West K, Cortese V, Konoby C, Weigel D. Effect of maternal antibodies on induction and persistence of vaccine-induced immune responses against bovine viral diarrhea virus type II in young calves. J Am Vet Med Assoc 2001;219(3):351-356. https://doi.org/10.2460/javma.2001.219.351. 
Rev Mex Cienc Pecu 2020;11(3):771-782

22. Morán P, Di Santo M, Gogorza L. Transmisión del virus de la diarrea viral bovina. Factores de riesgo en el ingreso y diseminación en los rodeos. Rev Vet 2006;17(1): 5058 . 